\title{
LA CULPABILIDAD DE LAS PERSONAS JURÍDICAS POR LA COMISIÓN DE INFRACCIONES ADMINISTRATIVAS: ESPECIAL REFERENCIA A LOS PROGRAMAS DE CUMPLIMIENTO
}

\author{
MANUEL GÓMEZ TOMILLO' \\ Universidad de Valladolid \\ gtomillo@der.uva.es
}

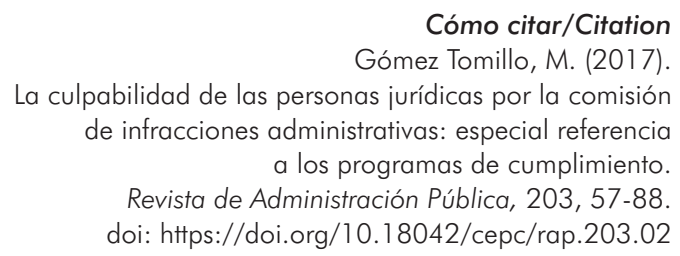

\section{Resumen}

Tanto la Ley 40/2015 como la jurisprudencia del Tribunal Constitucional español exigen la presencia de culpabilidad para sancionar administrativamente a las personas jurídicas. El trabajo desarrolla un concepto de culpabilidad válido para infracciones administrativas imputables a aquellas. Esencialmente se coincide con la idea desarrollada por la dogmática alemana y que lo concibe como defectuosa organización. En ese contexto se examina el papel que deben tener los programas de cumplimiento y su eficacia cara al cálculo de la concreta sanción. Se defiende la idea de que pueden operar atenuando y, excepcionalmente, excluyendo la responsabilidad. Se va, pues, más allá de lo que hasta ahora ha sido el criterio habitual, especialmente en el marco del derecho sancionador de la competencia.

1 Letrado del Tribunal Constitucional. Profesor titular de Derecho Penal. Acreditado a catedrático. 


\section{Palabras clave}

Culpabilidad; defecto de organización; infracciones administrativas; sanciones administrativas.

\section{Abstract}

Both Law 40/2015, as well as the jurisprudence of the Spanish Constitutional Court, requires the presence of culpability in order to punish legal persons. The paper deals with a concept of culpability for administrative infractions. Essentially it coincides with the idea developed by German dogmatics and conceives it as organisational fault. In that context, the role of compliance programs and their effectiveness in the determination of the specific sanction is examined. The idea is defended that they can operate by attenuating and, exceptionally, excluding responsibility. It goes beyond what has hitherto been the usual criterion, especially in the context of the law on competition.

\section{Keywords} tions.

Culpability; organisational fault; administrative sanctions; administrative sanc- 


\section{SUMARIO}

I. INTRODUCCIÓN. II. ESTADO DE DISCUSIÓN. III. LA CULPABILIDAD COMO DEFECTO ORGANIZATIVO. IV. ELEMENTOS INTEGRANTES DEL JUICIO DE CULPABILIDAD EN CASO DE INFRACCIONES ADMINISTRATIVAS IMPUTABLES A PERSONAS JURÍDICAS. V. ESPECIAL CONSIDERACIÓN DE LOS PROGRAMAS DE CUMPLIMIENTO ADOPTADOS CON CARÁCTER PREVIO A LA COMISIÓN DE LA INFRACCIÓN ADMINISTRATIVA. VI. LA CUESTIÓN DE LA CARGA DE LA PRUEBA.

\section{INTRODUCCIÓN}

Es conocido que en los ordenamientos jurídicos en los que se diferencia entre derecho penal y derecho administrativo sancionador, en este último, desde hace muchos años, es habitual la posibilidad de sancionar a las personas jurídicas $^{2}$. En los países europeos continentales, esa responsabilidad administrativa de las personas jurídicas ha sido habitualmente anterior en el tiempo a la responsabilidad penal, la cual, sin embargo, se va generalizando progresivamente.

2 Aunque la cuestión ahora mismo desborda el marco trazado para nuestro trabajo, quizá sea interesante poner de manifiesto en que el fenómeno del derecho administrativo sancionador no es tan universal como pensamos, toda vez que en numerosos países de nuestro entorno jurídico y cultural sigue siendo algo excepcional; dejando al margen a los países anglosajones, y singularmente a los Estados Unidos de América, en Europa hay múltiples países en los que no hay una verdadera potestad sancionadora de la Administración, con un predominio casi absoluto del derecho penal, como es el caso de Dinamarca o Suecia, por poner solo algún ejemplo; en general, puede verse el estudio de P. Rando Casermeiro (2010), La distinción entre el Derecho penaly el Derecho administrativo sancionador. Un análisis de politica jurídica, Valencia (págs. 69-72). Combate la idea conforme a la cual no hay propiamente un derecho administrativo sancionador en el sistema jurídico angloamericano: A. Betancor (2009), «Derecho administrativo sancionador en el sistema jurídico británico: Regulatory enforcement and sanctions Act», Revista General de Derecho Administrativo, 19, passim. 
Ello ha servido para que la teoría de la responsabilidad de las personas jurídicas haya alcanzado un notable alcance, siguiendo un camino inverso del habitual. Históricamente lo normal ha sido la influencia del derecho penal sobre el derecho administrativo sancionador, ante la evidencia de su común origen histórico y su más que probable unidad esencial. En este particular campo, por el contrario, el derecho administrativo sancionador ha tenido la oportunidad de ir por delante, allanando el camino a una potencial admisión de la responsabilidad penal de las personas jurídicas ${ }^{3}$. De hecho, es en Alemania donde en sentido estricto no es posible imputar delitos a las personas jurídicas, el lugar en el que se ha desarrollado, muy frecuentemente al hilo del derecho administrativo sancionador, tanto una importante teoría de la imputación de infracciones a las entidades como de la culpabilidad de estas. Este trabajo pretende, precisamente, centrarse en esta última cuestión.

Desde una perspectiva positiva, en España la problemática se presenta si se combinan, al menos, tres preceptos. Por una parte, el art. 28.1 de la Ley 40/2015 de 1 de octubre de Régimen Jurídico del Sector público contiene una declaración que posibilita la exigencia de responsabilidad sancionatoria administrativa a las personas jurídicas. Por otra, y sobre todo, el art. 29.3 a) de la misma ley establece que en la graduación de la sanción se atenderá al «grado de culpabilidad», de donde se deduce que conforme a la Ley la culpabilidad es necesaria para la imposición de la sanción (lo que, en todo caso, es inequívoco en la jurisprudencia del Tribunal Constitucional, tanto para personas físicas como jurídicas ${ }^{4}$. Por fin, el art. 9.3 de la Ley 2/1998, de 20 de febrero de

3 Me parece que en este contexto debe subrayarse la posición de Hirsch con la que coincidimos; este autor subraya que si, por una parte, en el derecho de las contravenciones se exige culpabilidad y, por otra, en ese contexto se reconoce capacidad de culpabilidad a las personas jurídicas, entonces, como consecuencia lógica, también se puede hablar de una culpabilidad de aquellas en derecho penal, en la medida en que no hay diferencias cualitativas entre una y otra rama del derecho: H. J. Hirsch (1993), «La cuestión de la responsabilidad penal de las asociaciones de personas», ADPCP (pág. 1110). En cuanto a la discusión sobre la naturaleza jurídica que presentan ambos sectores del ordenamiento jurídico, véase, por todos, M. Gómez Tomillo e I. Sanz Rubiales (2017), Derecho administrativo sancionador. Parte general, $4^{\mathrm{a}}$ ed., cap. 1.

4 Véanse, especialmente, SSTC 246/1991, de 19 de diciembre, FJ 2; 59/2008, de 14 de mayo, FJ 11 b); 185/2014 de 6 de noviembre, Fto. Jco. $3^{\circ}$ in fine. Un cambio en dicha orientación, como se propugna en España por algún autor, supondría un auténtico bandazo, absolutamente incompatible con las construcciones dominantes en los países de cultura jurídica avanzada. Sostienen la necesidad de exigir también culpabilidad en el ámbito del derecho administrativo sancionador: M. Kremnitzer y K. Ghanayim (2001), «Die Strafbarkeit von Unternehmen», ZStW, 113, pág. 551; 
Potestad Sancionatoria de las Administraciones Públicas del País Vasco, dispone que: «Cuando la eventual responsable sea una persona jurídica, el juicio de culpabilidad se hará respecto de la persona o personas físicas que hayan formado la voluntad de aquélla en la concreta actuación u omisión que se pretenda sancionar. En estos casos, no se podrá sancionar, por la misma infracción, a dichas personas físicas» ${ }^{5}$.

Quizá no sea superfluo en este contexto poner de relieve que cuando la Ley se refiere a la «culpabilidad» necesariamente está refiriéndose a la culpabilidad material, a la tercera de las características que acompañan a la acción, u omisión, en las más habituales definiciones de infracción administrativa. Ningún sentido tiene hablar aquí de culpabilidad procesal, vinculada a la presunción de inocencia y a la idea de si se cometió o no la infracción, o improvisar un concepto diverso, al margen de décadas de evolución del pensamiento jurídico-punitivo. Partimos, pues, de una definición que entiende aquella, coincidentemente con el concepto de delito, como acción u omisión, típica, antijurídica y culpable ${ }^{6}$. En consecuencia, se hace necesario delimitar qué debe entenderse por culpabilidad, cuando de personas jurídicas se trata.

subrayan la coincidencia con el concepto penal de culpabilidad, G. Rosenkötter (2002), Das Recht der Ordnungswidrigkeiten, 6 Auf., Stuttgart, 79; E. Göhler (2017), Ordnungswidrigkeitengesetz, 17 Auf., München, $\$$ vor 1, 30; K. Rebmann, S. Roth y S. Hermann (2016), Gesetz über Ordnungswidrigkeiten, 3 Auf., vor $\$ 1$, 45. En Alemania, sin embargo, se habla en relación con las infracciones administrativas de reprochabilidad, en vez de culpabilidad, como consecuencia de la dicción del $\$ 1 O \mathrm{Wi}$, pese a lo cual se suele concluir la identidad de ambos conceptos; véase, por ejemplo, $\mathrm{K}$. Rogall (2014), Karlsruher Kommentar zum Gesetz über Ordnungswidrigkeiten, 4 Auf., $\$ 1,8$.

5 Sobre tal norma en particular, véase I. López Carcamo e I. Lasagabaster Herrarte (2006), Ley de la Potestad Sancionadora. Comentario sistemático, págs. 197-198.

6 La literatura científica administrativista alemana se ha encargado de subrayar que la definición expuesta goza de plena aplicabilidad en relación con las infracciones administrativas: véanse, en Alemania, L. Treder (1996), Ordnungswidrigkeitenrecht, Heidelberg, págs. 9 y passim; R.-D. Thiesen (2002), Ordnungswidrigkeitenrecht, págs. 50-51. En Alemania es un concepto que se desprende del $₫ 1$ de la $O W i G$. Este último precepto la define como «acción antijurídica y reprochable que realiza el tipo de una ley y que permite la sanción por medio de una multa», de donde se deducen claramente todos los elementos de la definición expuesta en el texto, la cual es coincidente con la de delito. Véanse, asimismo, W. Mitsch (2005), Recht der Ordnungswidrigkeiten, 2 Auf., $\$$ 6, 2; H-H. Jescheck y T. Weigend (2003), Tratado de Derecho penal. Parte general, 5a ed., $\$ 7$, V, 5; G. Rosenkötter, Das Recht der Ordnungswidrigkeiten, 14; J. Bohnert (2000), Karlsruher Kommentar zum Ordnungswidrigkeitengesetz, 
La doctrina del Tribunal Constitucional español en la materia ayuda poco. En las conocidas STC 246/1991, de 19 de diciembre, FJ 2 (y, posteriormente, en la STC 129/2003, de 30 de junio, FJ 8), se dice que:

Este principio de culpabilidad rige también en materia de infracciones administrativas, pues en la medida en que la sanción de dicha infracción es una de las manifestaciones del ius puniendi del Estado, resulta inadmisible en nuestro ordenamiento un régimen de responsabilidad objetiva o sin culpa (STC

Einleitung, págs. 162 y ss.; en Austria, véanse N. Raschauer y W. Wessely (2005), Verwaltungsstrafrecht. Allgemeiner Teil, Wien, Graz, págs. 46 y ss.; U. Thiess, Ordnungswidrigkeitenrecht, págs. 122 y ss. Incluso se sostiene tal punto de vista partiendo de tesis mixtas en lo que respecta a la diferenciación de delitos e infracciones; véanse Rebmann-Roth-Hermann (2016: vor $\$ 1$, 15, $\$ 1,1)$; K. Rogall (2014: vor $\$ 1$, 10, $\$ 1,1, \$ 8,1)$; e igualmente se sostiene entre los escasos partidarios de una distinción material, M. Lemke y A. Mosbacher (2005), Ordnungswidrigkeitengesetz, 2 Auf. 2005, Einleitung, 22.

Subrayan en Italia la necesidad de que concurran las características de la tiicidad, antijuridicidad y culpabilidad, por ejemplo, E. Paliero y A. Travi (1988), Le sanzioni amministrative, págs. 217 y ss.; P. Cerbo (1999), Le sanzioni amministrative, págs. 67 y passim.

En España, véanse, entre otros, T. Cano Campos (2001), "Non bis in idem, prevalencia de la vía penal y teoría de los concursos», $R A P, 156$, pág. 196, n. 6; M. Izquierdo Carrasco (2007), «Un caso de aplicación insuficiente del principio de culpabilidad propio del Derecho administrativo sancionador: el caso de las denominadas "falsas alarmas"”, Justicia Administrativa, 37, pág. 34; F. García Gómez de Mercado, Sanciones administrativas. Garantias, derechos y recursos del presunto responsable (2002), Granada, pág. 68; F. González Navarro (2007), Comentarios a la Ley de Régimen Jurídico de las Administraciones Públicas y Procedimiento Administrativo Común, t. II (4a ed. junto con J. González Perez), pág. 2890; S. Añíbarro Pérez y B. Sesma Sánchez (2005), Infracciones y sanciones tributarias, Valladolid, pág. 61; A. J. García Gómez (2002), La simple negligencia en la comisión de infracciones tributarias, Madrid, Barcelona, págs. 67 y passim; J. J. Zornoza Pérez (1992), El sistema de infracciones y sanciones tributarias (Los principios constitucionales del derecho sancionador), Madrid, págs. 174 y ss.; J. Suay Rincón (1989), "Principio de legalidad en materia sancionadora y su eficacia en el ámbito del crédito», $R D B B, 34$, págs. 25-26, subrayando, con razón, que no porque no exista tal definición en la Ley esta no existe, ya que la Constitución obliga a su búsqueda a partir de la necesidad de proyectar sobre las infracciones el principio de legalidad. L. Parejo Alfonso (2006), La disciplina urbanistica... proporciona una definición próxima en el contexto del derecho urbanístico, pero en la que se detectan algunas ausencias: «actuación urbanística sancionable típica y culpable», pág. 132. 
76/1990). Incluso este Tribunal ha calificado de «correcto» el principio de la responsabilidad personal por hechos propios — principio de la personalidad de la pena o sanción- (STC 219/1988). Todo ello, sin embargo, no impide que nuestro Derecho Administrativo admita la responsabilidad directa de las personas jurídicas, reconociéndoles, pues, capacidad infractora. Esto no significa, en absoluto, que para el caso de las infracciones administrativas cometidas por personas jurídicas se haya suprimido el elemento subjetivo de la culpa, sino simplemente que ese principio se ha de aplicar necesariamente de forma distinta a como se hace respecto de las personas físicas. Esta construcción diferente de la imputabilidad de la autoría a la persona jurídica nace de la propia naturaleza de ficción jurídica a la que corresponden estos sujetos. Falta en ellos el elemento volitivo en sentido estricto, pero no la capacidad de infringir las normas a las que están sometidos. Capacidad de infracción y, por ende, reprochabilidad directa que deriva del bien jurídico protegido por la norma que se infringe y de la necesidad de que dicha protección sea realmente eficaz ${ }^{7}$.

Es decir, de lo afirmado por el Tribunal parece deducirse que se equipara culpabilidad y capacidad infractora. Sin embargo, cabe afirmar la existencia de capacidad de infracción y, por el contrario, sostener la ausencia de culpabilidad, tanto en las personas físicas (piénsese, por ejemplo, en los casos de inimputabilidad, donde se ha infringido la norma, pero no se es culpable) como en las jurídicas ${ }^{8}$. Por ello mismo, entiendo que debe profundizarse algo más en la materia. En este trabajo apuntamos lo que entendemos constituyen las paredes maestras de la culpabilidad característica de las personas jurídicas cuando de infracciones administrativas se trata?

7 Sobre la citada sentencia, véanse B. Lozano Cutanda (1992), «La responsabilidad de la persona jurídica en el ámbito sancionador administrativo (a propósito de la STC 246/1991)», RAP, 129, págs. 211 y ss.; I. Lazcano Brontons (2006), "Culpabilidad», I. Lasagabaster Herrarte (dir.), Ley de la Potestad Sancionadora. Comentario sistemático, pág. 111; A. Nieto Martín (1996), Fraudes comunitarios (Derecho penal económico europeo), págs. 205-209.

8 Críticamente también, véase M. Bajo Fernández (1996), «La responsabilidad de las personas jurídicas en el Derecho administrativo español», en S. Mir Puig y D. M. Luzón Peña (coords.), Responsabilidad penal de las empresas y de sus órganos y responsabilidad por el producto, Barcelona, pág. 28, donde afirma que "[p]or más circunloquios que la sentencia realiza, no sale del círculo vicioso de que la persona jurídica tiene capacidad de culpabilidad porque tiene capacidad de infracción y de la identificación simplificadora de la culpabilidad con la infracción».

9 No sin razón se ha subrayado el carácter confuso de la culpabilidad en el derecho administrativo sancionador: A. Nieto (2012), Derecho administrativo sancionador, pág. 572; o los numerosos comentarios que ha suscitado: J. Pemán Gavín (2000), 


\section{ESTADO DE LA DISCUSIÓN}

Al abordar la problemática de la culpabilidad de las personas jurídicas, cabe sostener, en síntesis y al menos, tres opciones de partida ${ }^{10}$. Por un lado, estimar que no es preciso mantener la exigencia de culpabilidad cuando el infractor es una persona jurídica ${ }^{11}$. Por otro, acudir a una culpabilidad por representación, es decir, a la persona jurídica se le imputa la culpabilidad de la persona física realmente actuante ${ }^{12}$. Por fin, cabe elaborar una forma de culpabilidad específica para las empresas o entes colectivos.

Desde nuestro punto de vista, no puede compartirse la teoría negadora de la necesidad de mantener la exigencia de culpabilidad en las personas jurídicas infractoras. Aceptada la responsabilidad de las personas jurídicas por la comisión de infracciones administrativas, tanto de lege lata como de lege feren$d a$, existen sólidas razones que apoyan la exigencia de culpabilidad también cuando dichas infracciones se imputan a entidades distintas de las personas físicas ${ }^{13}$.

En primer lugar, debe considerarse que rechazar la exigencia de culpabilidad en las personas jurídicas puede implicar una inaceptable afección al

El sistema sancionador español. Hacia una teoría general de las infracciones y sanciones administrativas, pág. 292. Alerta de la necesidad de calibrar muy bien la exigencia de responsabilidad culpable M. Casino Rubio (2015), «La potestad sancionatoria de la Administración y vuelta a la casilla de salida», $D A, 2, \mathrm{n}$. 22. Parecen exigir la culpabilidad también en el caso de sanciones a las personas jurídicas, E. García de Enterría y T. R. Fernández (2015), Curso de Derecho administrativo, t. II, 14a ed., pág. 182.

10 Véase, por todos, M. Engelhardt (2010), Sanktionierung von Unternehmen und compliance. Eine rechtssvergleichende Analyse des Straf-und Ordnungswidrigkeitenrechts in Deutschland und den USA, Berlin, págs. 353 y ss.

11 Se trata de una idea mantenida en Alemania por B. Schünemann. Este autor entiende que la única posibilidad de legitimar la imposición de una sanción, penal o administrativa, a las personas jurídicas prescindiendo de la culpabilidad radica en lo que denomina el estado de necesidad del bien jurídico — véase B. Schünemann (1979), Unternehmenskriminalität und Strafrecht, págs. 235 y ss.—. Hay una evolución en su pensamiento en la que no podemos entrar, sobre este particular véase C. Gómez-Jara Díez (2005), La culpabilidad penal de la empresa, Madrid: Marcial Pons, págs. 170 y ss.

12 Probablemente, y con matices, es la posición de H. J. Hirsch (1993: 1110 y ss.).

13 En sentido muy próximo, véase M. Brender (1989: 111 y ss.), quien pone de manifiesto lo adecuado del derecho de las Ordnungswidrigkeiten para su desarrollo por su carácter más joven, considerando, al tiempo, el creciente poder de las empresas; véase, asimismo, A. Nieto Martín (2008: 115 y ss.). 
principio de proporcionalidad ${ }^{14}$. En efecto, si se prescinde de la culpabilidad de las personas jurídicas, las sanciones frente a estas se deben fundamentar exclusivamente sobre bases preventivas, se trataría de disuadir de la comisión de determinados comportamientos. Al no existir el límite de la culpabilidad, cabe la imposición de sanciones muy elevadas, desproporcionadas, para conseguir los fines perseguidos, sean estos nimios o legítimos.

En segundo lugar, la tesis aquí criticada puede plantear problemas desde el punto de vista del principio de igualdad, en la medida en que se sostenga que, precisamente, el juicio de culpabilidad tiene entre otras funciones la de individualizar la responsabilidad del infractor, esto es, la de considerar los factores individuales de la infracción. De esta manera, se atiende en este momento a la desigualdad de los sujetos entre sí, incorporándose al derecho sancionador el pensamiento de que no solo debe tratarse lo igual como igual, sino lo desigual, como desigual ${ }^{15}$. Prescindir de la culpabilidad de las personas jurídicas, en el derecho administrativo sancionador o en el derecho penal, lleva a tratar igual a quien no hay nada que censurarle que a quien sí que se le puede reprochar algo, por ejemplo, un déficit organizativo.

En tercer lugar, aceptada la identidad ontológica entre infracciones y delitos, debe optarse por construcciones que permitan, en la medida de lo posible, mantener el paralelismo entre ambas categorías, esto es, la mayor homogeneidad dentro del sistema punitivo, estableciendo el más elevado nivel de garantías posibles, considerando la alta capacidad del derecho administrativo sancionador para incidir en la vida y patrimonio de las personas. De lo contrario se incidiría en una responsabilidad sancionatoria por el riesgo, que tiene su fundamento en el ámbito del derecho civil, pero que carece de sentido en un derecho de carácter punitivo.

Por último, como hemos destacado ya, el art. 29.3 a) de la Ley 40/2015 parece inequívoco al establecer que en la graduación de la sanción se atenderá al "grado de culpabilidad", de donde se deduce que la culpabilidad es necesaria para la imposición de la sanción, sin que de dicha previsión se exceptúen

14 De tal posibilidad son conscientes quienes sostienen la necesidad de prescindir de la culpabilidad, pues insisten en el sometimiento al principio de proporcionalidad, B. Schünemann (1979: 241).

15 Véase, por ejemplo, A. Torío López (1985), «El concepto individual de culpabilidad», $A D P C P$, pág. 300; partiendo de un concepto diferente, la idea se encuentra también presente, por ejemplo, en E. Octavio de Toledo y S. Huerta Tocildo (1985), Derecho Penal. Parte general, 2a ed., pág. 298; S. Mir Puig (2016), Derecho penal. Parte general, 10 ed., 20, V, 50 y 51. 
las personas jurídicas (lo cual, insistimos, es inequívoco en la jurisprudencia del Tribunal Constitucional, dictada al hilo de sanciones administrativas).

Asumida la necesidad de culpabilidad en el seno de las infracciones administrativas imputables a las personas jurídicas, conforme a lo expresado, hay quien propugna la llamada teoría de la representación, es decir, imputar a la persona jurídica la culpabilidad de la persona física. Probablemente, ese sea el criterio del citado art. 9.3 de la Ley 2/1998, de 20 de febrero de Potestad Sancionatoria de las Administraciones Públicas del País Vasco: «Cuando la eventual responsable sea una persona jurídica, el juicio de culpabilidad se hará respecto de la persona o personas físicas que hayan formado la voluntad de aquélla en la concreta actuación u omisión que se pretenda sancionar. En estos casos, no se podrá sancionar, por la misma infracción, a dichas personas físicas». Desde nuestro punto de vista, también debe rechazarse tal construcción, al menos, por dos razones. Por una parte, con ella se pierden algunas de las ventajas de atribuir responsabilidad a las personas jurídicas. En concreto, aparecen las dificultades asociadas al tener que individualizar responsabilidades en estructuras empresariales complejas (mal puede trasladarse a una persona jurídica la culpabilidad de una física cuyas condiciones se desconocen). Por otra, la teoría de la representación, en última instancia, implica una responsabilidad por hechos de otro, incompatible con el principio de personalidad de las sanciones ${ }^{16}$. En definitiva, supone una confusión de responsabilidades: la de la persona física y la de la jurídica; se ignora que existen sólidas razones para atribuir responsabilidad a esta última que responde por su propio injusto y una culpabilidad diferenciada.

A la vista de lo expuesto, propugnamos, junto con una amplia corriente de opinión, la capacidad de culpabilidad en las personas jurídicas, conforme a una construcción específica, adaptada a estas especiales estructuras organizativas $^{17}$. El problema es la delimitación conceptual de esa culpabilidad característica de las personas jurídicas. A ello dedicamos el siguiente apartado.

16 En el mismo sentido, véanse, por todos, C. Gómez-Jara Díez (2005: 141 y ss.); J. M. Zugaldía Espinar (2001), «La responsabilidad penal de las personas jurídicas en el Derecho penal español», El Nuevo Derecho penal español. Estudios Penales en Memoria del Profesor José Manuel Valle Muñiz, pág. 893; B. Feijoo Sánchez (2002), Sanciones para empresas por delitos contra el medio ambiente, Madrid, págs. 56 y ss., donde proporciona ulterior información bibliográfica; S. Bacigalupo Sagese (1998), Responsabilidad penal de las personas jurídicas, págs. 176 y ss.

17 Reclama una culpabilidad específica para las personas jurídicas F. Medina Osório (2006), Direito administrativo sancionador, pág. 470. Véase un análisis de las posiciones críticas con la posibilidad de aceptar la capacidad de culpabilidad en las personas jurídicas en C. Gómez-Jara Díez (2005: 81 y ss.). 


\section{LA CULPABILIDAD COMO DEFECTO ORGANIZATIVO}

Como hemos expresado, en el juicio de culpabilidad de las personas jurídicas se debería proceder a considerar, del mismo modo que ocurre en las personas físicas, los factores individuales, de la infracción, ignorados en el juicio de antijuridicidad. Partiendo de tales postulados, desde nuestra perspectiva, probablemente la construcción más adecuada en el estado actual de la ciencia jurídica es, con ciertos matices, la desarrollada al hilo de las infracciones administrativas por Tiedemann, conforme a la cual debe hablarse de culpabilidad de las personas jurídicas por defecto de organización ${ }^{18}$. Desde tal punto de

18 K. Tiedemann (1988), "Die "Bebüssung” von Unternehmen nach dem 2 Gesetz zur Bekämpfung der Wirtschaftskrimimalität», NJW, 41, pág. 1172; sobre el desarrollo que efectúa su discípulo M. Brender (1989: particularmente 105 y ss.).

De alguna manera se puede entender que la doctrina administrativista española acepta en algunos casos el modelo propuesto. M. Rebollo Puig (1989), Potestad sancionadora, alimentación y salud pública, Madrid, pág. 769 y, sobre todo, 771; recoge la posibilidad sin pronunciarse sobre la misma M. J. Gallardo Castillo (2008), Los principios de la potestad sancionadora, pág. 210, n. 190; véase, sin utilizar expresamente tal construcción; del mismo modo, Lozano Cutanda ha sostenido que debe imputarse a la persona jurídica la responsabilidad por defecto de vigilancia de sus empleados (1992: 227); con acierto, expresamente acoge la construcción de Tiedemann, A. de Palma del Teso (1996), El principio de culpabilidad en Derecho administrativo sancionador, Madrid, pág. 203, si bien como criterio de atribuibilidad de la infracción, con lo que, entiendo, se confundirían los planos de la culpabilidad y de la tipicidad; de la misma autora (2001), «Culpabilidad», en «Infracciones, Sanciones y Procedimiento Administrativo Sancionador", Justicia Administrativa, número extraordinario, singularmente págs. 29 y ss. Entre los penalistas que acogen el criterio, véanse, por ejemplo, A. Nieto Martín (1996: 202 y ss.); J. M. Zugaldía Espinar (1994), "Capacidad de acción y capacidad de culpabilidad de las personas jurídicas», CPC, pág. 624; L. Rodríguez Ramos (1996), «Societas delinquere potest! Nuevos aspectos dogmáticos y procesales de la cuestión", La Ley, 3 de noviembre de 1996, pág. 4; B. Feijoo Sánchez (2002: 69 y ss.), quien, sin embargo, la rechaza en el marco del derecho penal, estimándola propia de sanciones administrativas (lo que no es compaginable con el carácter unitario de delitos e infracciones administrativas, en nuestra concepción). Se trata de una construcción que también se maneja en Italia en el contexto que nos ocupa: así, véase, por todos, A. Adelmo Manna (2003), «La c.d. responsabilità amministrativa delle persone giuridiche: il punto di vista del penalista», Cass. pen., 3, donde en la n. 52 se remite a la obra de K. Tiedemann (1995), «La responsabilità penale delle persone giuridiche in diritto comparato", RIDPGS, págs. 615 ss. En los Estados Unidos también se han manejado criterios próximos, véase C. Gómez-Jara Díez (2005: 95-107). Sostiene que se trata de un concepción que se ha adoptado en las infracciones en materia de 
vista, se trataría del juicio de censura que se formula frente a una persona jurídica porque ha omitido la adopción de las medidas de precaución que le son exigibles para garantizar un desarrollo ordenado y no infractor de la actividad relativa al hecho de la empresa ${ }^{19}$. Tal culpabilidad es particularmente patente en las hipótesis en las que el hecho protagonizado por la persona jurídica no se debe a la actuación particular de un sujeto enmarcado en aquélla, sino al cúmulo de operaciones individuales de personas físicas insertas en la estructura propia del ente colectivo de que se trate ${ }^{20}$. Se trataría de un juicio complejo, en el que habría que examinar, de igual manera que en el de la culpabilidad de las personas físicas, una pluralidad de elementos (como tendremos ocasión de exponer en el siguiente punto). Se trataría, en fin, de un juicio que no estaría presente de forma automática en los casos en los que se verifique la realización de los elementos objetivos del tipo, sino que, al contrario, puede

competencia por parte de la Unión Europea, y la legislación italiana; M. J. Guardiola Lago (2004), Responsabilidad penal de las personas jurídicas y alcance del artículo 129 del Código Penal, Valencia, págs. 65-66.

Críticamente hacia la idea de Tiedemann, véase, por ejemplo, en Alemania, K. Rogall (2014: $\$ 30,6)$; o entre los penalistas de aquel país, C. Roxin (1997), Derecho penal. Parte general, trad. D. M. Luzón Peña et al., $\$ 8,56$ c, para quien sigue siendo una ficción, ya que la organización defectuosa no puede ser desarrollada por la persona colectiva, sino por sus directivos; en igual sentido, L. Greco (2015), «Shuldprinzip und Strafbarkeit juristischer Personen», GA, pág. 508. En España, M. Bajo Fernández (1996: 31); S. Bacigalupo Sagesse (1998: 218-219); L. Gracia Martín (1993), «La cuestión de la responsabilidad penal de las personas jurídicas», Act. Penal, 39, pág. 602; M. Pérez Manzano (1995), «La responsabilidad penal de las personas jurídicas», $A P$, 2, págs. 21 y ss., donde sostiene que se confunde el plano de la culpabilidad con el de lo injusto; ampliamente, véase C. Gómez-Jara Díez (2005: 156 y ss.); véase el resumen que proporciona en España M. J. Guardiola Lago (2004: 66-67). Rechazaba, sin más, el planteamiento de la culpabilidad como defecto de organización la Circular 1/2011 de la Fiscalía General del Estado.

19 Casi no hace falta insistir que el juicio de censura debe entenderse desprovisto de toda clase de connotación ética, toda vez que los comportamientos imputados a las personas jurídicas carecen por completo de coloración moral. En consecuencia, equivale a desaprobación de la conducta, lo cual se puede determinar de acuerdo con parámetros sociales, culturales o puramente jurídicos, pero en absoluto éticos; en general, véase J. Cigüela Sola (2015), La culpabilidad colectiva en Derecho penal, págs. 247 y ss. Por otra parte, como resulta evidente, se trata de un juicio de carácter eminentemente valorativo; destaca este aspecto M. Brender (1989: 112).

20 No obstante, comparto la idea de A. Nieto Martín, conforme a la cual el nivel jerárquico del autor individual es un indicador bastante fiable del grado de culpabilidad (2008: 162-163). 
excluir la responsabilidad sancionatoria, cuando la persona jurídica acredite la correcta organización cara a la evitación de ilícitos administrativos (al respecto, debe recordarse que la carga de la prueba de la exclusión de la culpabilidad recae sobre quien lo alega ${ }^{21}$. Entiendo que, de alguna manera, la construcción apuntada es coherente con la jurisprudencia del Tribunal Supremo, Sala de lo Contencioso-Administrativo, en relación con la exención de responsabilidad sancionatoria tributaria en caso de interpretación razonable de tales normas, prevista hoy en el art. 179.2 d) LGT, como causa eximente de responsabili$\mathrm{dad}^{22}$. Apenas cabe duda de que, si hubo una intepretación razonable de la norma, no hubo defecto de organización y, por consiguiente, tampoco culpabilidad, como apunta el citado tribunal ${ }^{23}$.

21 Sobre la cuestión volveremos con detalle en el apartado VI. De lo expresado en el texto se deduce que no compartimos el criterio del propio Tiedemann conforme al cual la empresa no puede librarse de la sanción mediante la prueba de una organización eficiente; como tampoco entendemos la concepción de su discípulo M. Brender, conforme al cual la empresa solo puede eximirse de responsabilidad probando que el hecho de conexión no existe (1989: 117). Se trata de uno de los puntos de la construcción deTiedemann que más críticas ha suscitado; así, en España, entre otros, B. Feijoo Sánchez, quien subraya la fusión de la culpabilidad con elementos objetivos del tipo (2002: 70 y ss.); interpreto en el mismo sentido a H. Achenbach, «Sanciones con las que se pueden castigar a las empresas y a las personas que actúan en su nombre en el Derecho alemán» (1995), Libro homenaje a Claus Roxin, pág. 405; véase, asimismo, A. Nieto Martín (1996: 208), quien afirma que «no podemos proclamar la culpabilidad propia de la persona jurídica y luego prescindir de ella o presumir su existencia... el camino correcto estriba en admitir la falta de culpabilidad de la persona jurídica en aquellos supuestos en los que se demuestre que la empresa ha puesto toda la diligencia necesaria para que no se cometan ilícitos en su interior»; sobre la cuestión véase C. Gómez-Jara Díez (2005: 153 y ss.), quien en la pág. 159 utiliza la misma cita del anterior autor.

22 El análisis de la cuestión desborda el marco posible de nuestro trabajo; véase, por todos, S. Aníbarro Pérez (1999), La interpretación razonable de la norma como eximente de responsabilidad por infracción tributaria, Valladolid.

23 Quizá quepa aquí, por todas, la cita de la STS de 18 de julio de 2013, Sala de lo Contencioso-Administrativo, FJ 10 (recurso de casación 6498/2010): «El principio de culpabilidad constituye un elemento básico a la hora de calificar la conducta de una persona como sancionable, es decir, es un elemento esencial en todo ilícito administrativo, y es un principio que opera no sólo a la hora de analizar la conducta determinante de la infracción, sino también sobre las circunstancias agravantes. En el ámbito del Derecho tributario sancionador el Tribunal Supremo ha venido construyendo en los últimos años una sólida doctrina en el sentido de vincular la culpabilidad del sujeto infractor a la circunstancia de que su conducta no se halle amparada por una interpretación jurídica razonable de las normas fiscales aplicables. Especialmente, 
No podemos entrar en detalle en el análisis de serias construcciones alternativas a la aquí expresada ${ }^{24}$. Entre ellas quizá destaque en España la de Gómez-Jara. Para este autor la culpabilidad de la persona jurídica equivale a una cultura empresarial de incumplimiento de la legalidad ${ }^{25}$. Sin embargo,

cuando la Ley haya establecido la obligación a cargo de los particulares de practicar operaciones de liquidación tributaria, la culpabilidad del sujeto infractor exige que tales operaciones no estén respondiendo a una interpretación razonable de la norma tributaria, pues si bien esta interpretación puede ser negada por la Administración, su apoyo razonable, sobre todo si va acompañada de una declaración correcta, aleja la posibilidad de considerar la conducta como infracción tributaria, aunque formalmente incida en las descripciones del art. 79 de la misma Ley General Tributaria (Sentencias, entre otras muchas, de 29 de enero, 5 de marzo, 7 de mayo y 9 de junio de 1993; y 24 de enero y 28 de febrero de 1994 y 6 de julio de 1995)».

24 Por ejemplo, resulta muy próxima a la aquí defendida la propuesta de Engelhart, el cual prefiere hablar de un deficitario clima de empresa (2010: 673). El propio Engelhart reconoce que se trata de una construcción que hunde sus raíces en la de Tiedemann (ibid: 675). Sostiene que existe tal deficitario clima de empresa cuando esta no adoptó las medidas suficientes para impedir el riesgo que se materializó en la actuación individual del personal de la organización (ibid.: 673). Para construcciones alternativas, véase L. Zúñiga Rodríguez (2010), Bases para un modelo de imputación de responsabilidad penal a las personas jurídicas, pág. 240; S. Bacigalupo Sagesse (1998: particularmente, 169 y ss.). Esta última autora opta por defender un modelo de culpabilidad basada en la necesidad de imponer una pena cuando así lo exija el restablecimiento de la vigencia de la norma, esto es, fundada en la prevención general positiva (véase, por ejemplo, págs. 199 y ss., 398-299), sólida posición con la que no compartimos los postulados dogmáticos de los que parte; en general, véase la obra de C. Gómez-Jara (2005: 139 y ss., 161 y ss. y 180 y ss.) y A. Nieto Martín (2008: 134 y ss.).

25 C. Gómez-Jara Díez (2012), «Fundamentos de la responsabilidad penal de las personas jurídicas», Tratado de responsabilidad penal de las personas jurídicas, págs. 117, 124, entre otras de sus obras. La idea de la cultura empresarial como base de la responsabilidad de las personas jurídicas aparece en el derecho angloamericano; concretamente la propone Bucy, quien sostiene que la posesión de un diferente ethos otorga sentido a la atribución de responsabilidad corporativa - P. H. Bucy (1991), "Corporate ethos: a standard for imposing corporate criminal liability», Minnesota Law Review, 75, pág.1095-; el criterio aparece en el United States Sentencing Commission Guidelines Manual, \$8B2.1, «Effective Compliance and Ethics Program»; véase el Código Penal australiano, 12.3. (1); James Gobert y Maurice Punch (2003), Rethinking corporate crime, pág. 74. No deja de ser interesante que en la misma doctrina anglosajona se exprese que ese corporate ethos es el equivalente funcional a la actitud o a la predisposición conductual característica del ser humano, Chistopher Harding (2007), Criminal Enterprise. Individuals, organisations and criminal responsibility, pág. 145. 
entiendo que una construcción de esta naturaleza, ciertamente sugerente, resulta excesivamente ambigua ${ }^{26}$ y determina una excesiva restricción de las posibilidades sancionatorias, reducidas al ámbito de lo excepcional, puesto que una cultura tal es más propia de las organizaciones criminales que de las personas jurídicas que operan en el mercado y que, excepcionalmente, incurren en un delito, o, en lo que a nosotros nos interesa aquí, una infracción administrativa ${ }^{27}$. Por otra parte, la culpabilidad requiere de una conexión con el ilícito cometido y la idea de cultura empresarial puede encontrarse excesivamente desligada del hecho concreto que determina la responsabilidad, puesto que es un concepto que implica una proyección dilatada en el tiempo. Dicho con otras palabras, a una empresa recién creada claramente se le puede imputar una infracción administrativa (o un delito), pero difícilmente se puede decir que carezca de una cultura de cumplimiento, puesto que esta no parece que se pueda improvisar de la noche a la mańana (aunque sí un defecto organizativo,

26 Pone de manifiesto la ambigüedad de la construcción Celia Wells (2001), Corporations and criminal responsibility, 2 ed., pág. 138; del mismo modo resulta significativa la crítica de la propia doctrina australiana, en cuyo seno de afirma que «Such an amorphous concept as 'corporate culture' provides considerable scope for the raising of a reasonable doubt...» — véase Jonathan Clough (2007), "Bridging the theoretical gap: the search for a realist model of corporate criminal liability», Criminal Law Forum, 283-. Del mismo modo, no puede dejar de considerarse cómo en Canadá se rechazó el criterio con el argumento, precisamente, de su vaguedad: Government of Canada (2002), Corporate Criminal Liability. Discussion Paper, 11. Incluso entre los defensores del modelo se acepta que proporciona ciertas dosis de incertidumbre: N. Cavanagh (2011), "Corporate criminal liability: an assessment of the models of fault», Journal of Criminal Law, 440. Véase una amplia exposición y crítica en J. Cigüela Sola (2015: 207 y ss.).

27 Comparte el punto de vista del texto J. L. de la Cuesta Arzamendi (2011), «Responsabilidad penal de las personas jurídicas en el Derecho español», Revista Electrónica de la AIDP, A-05:9, quien por ello se adhiere a la idea de Feijoo Sánchez, quien a su vez habla de falta de cultura de cumplimiento de la legalidad ( LLa responsabilidad penal de las personas jurídicas», págs. 107 y ss.); véase, asimismo, la crítica de este último autor a la construcción de Gómez Jara (2014), «Fortalezas, debilidades y perspectivas de la responsabilidad penal de las personas jurídicas», en M. Ontiveros Alonso (coord.), La responsabilidad penal de las personas juridicas, Valencia, págs. 165 y ss., reflejando aspectos positivos en págs. 168 y ss. que pueden ser compartidos; véase, asimismo, crítico con la construcción, J. M. Palma Herrera (2014), «El papel de los compliance en un modelo vicarial de responsabilidad penal de la persona jurídica», Procedimientos operativos estandarizados y responsabilidad penal de la persona jurídica, págs. 183 ss., subrayando la ausencia de una base legal para semejante criterio en pág. 184. 
idea que tiene un carácter más puntual). Por último, un injusto consistente en la ausencia de una determinada cultura implicaría claramente una transición de un derecho punitivo del hecho a una especie inasumible de derecho sancionatorio de autor, asociado al modo de conducción de la vida en nuestro caso social, empresarial u organizativa (SSTC 150/1991 de 4 de julio, FJ 4; 185/2014 de 6 de noviembre, FJ 3).

Pese a lo expuesto, en el marco estricto del derecho penal, la expresada posición ha tenido un relativo acogimiento en la jurisprudencia penal del Tribunal Supremo, si bien más como criterio de imputación de delitos que como cuestión de culpabilidad. El Alto Tribunal ha requerido para la exigencia de responsabilidad penal de la persona jurídica analizar si el delito cometido por la persona física en el seno de aquella "ha sido posible, o facilitado, por la ausencia de una cultura de respeto al Derecho». Dentro de esa cultura de respeto se incluiría la implementación de un adecuado programa de cumplimiento (véanse SSTS 154/2016 de 29 de febrero o en la 221/2016 de 16 de marzo, FJ 5 , in fine). Lo cierto es que, por un lado, el Tribunal Supremo hasta la fecha no ha analizado la existencia o inexistencia de una cultura de cumplimiento como causa de atipicidad en casos concretos. Por otro, se trata de una cuestión muy controvertida, en el seno del propio tribunal, toda vez que en el voto particular formulado por siete magistrados a dicha sentencia se sostiene un criterio distinto: «Los presupuestos específicos de la responsabilidad penal de las personas jurídicas o elementos del tipo objetivo a que se refiere la sentencia mayoritaria vienen expresamente definidos por el Legislador en los párrafos a) y b) del párrafo $1^{\circ}$ del art. 31 bis $\mathrm{CP}$, y estos son los que deben ser probados por la acusación, y expresamente reflejados en el relato fáctico de la sentencia, para permitir la subsunción jurídica adecuada $»^{28}$.

28 Aun cuando no podemos entrar en detalles en un trabajo de estas características, al margen de lo criticable que puede resultar el criterio de la cultura de cumplimiento, llama la atención la incorrección del criterio que asume el Tribunal, especialmente por la imposibilidad de que la ausencia de una cultura determinada facilite nada, haga posible o facilite el delito o la infracción administrativa de cualquier forma. Dicho de otra manera, el Alto Tribunal parece afirmar que de una omisión (el no haber promovido una cultura determinada) puede derivarse algo (el delito), cuando un abstenerse de actuar es una nada fáctica, y de la nada, nada puede surgir, ex nihilo nibil fit. Puede ser ilustrativa la remisión a la discusión que en términos idénticos se desarrolla en el marco de los delitos de comisión por omisión. 


\section{ELEMENTOS INTEGRANTES DEL JUICIO DE CULPABILIDAD EN CASO DE INFRACCIONES ADMINISTRATIVAS IMPUTABLES A PERSONAS JURÍDICAS}

Los problemas, evidentemente, no se han solucionado con la adopción de un determinado modelo de culpabilidad. Se hace necesario precisar qué elementos lo integran, o han de examinarse en ella, máxime si se considera el reiteradamente citado art. 29.3 a) de la Ley 40/2015 que requiere la concurrencia de tal culpabilidad y la configura como criterio graduador de la sanción, sin exceptuar a las personas jurídicas, coherentemente con la jurisprudencia constitucional.

Es conocido como la culpabilidad en las elaboraciones habituales destinadas a las personas físicas, se configura como un juicio complejo integrado por una pluralidad de elementos: la conciencia de la antijuridicidad, la imputabilidad, la ausencia de causas de disculpa, etc. ${ }^{29}$. Sin embargo, lo característico de la práctica totalidad de los elementos citados es que están diseñados pensando en personas naturales, no en entes colectivos. Así, se ha sostenido que dentro de la categoría culpabilidad característica de las personas jurídicas es preciso eliminar aquellos elementos pensados para un sujeto con características físicas. Aceptando tal punto de partida, sin embargo, debe estarse a las circunstancias del caso concreto, de forma que la falta de culpabilidad de la persona física que actúa en nombre de la jurídica puede en ocasiones excluir la responsabilidad de esta última o, al contrario, ser un síntoma de un defecto organizativo. Los elementos que juzgamos deben incluirse en el juicio de culpabilidad de las personas jurídicas, especialmente si se define como defecto organizativo de la entidad, serán los siguientes.

En primer lugar, es aquí donde se debe plantear si ha habido o no una adecuada vigilancia, supervisión o control sobre el personal sin poder de dirección. Se trata, evidentemente, de un dato de carácter valorativo, tan solo susceptible de ser afirmado o negado en contacto con las circunstancias del caso concreto ${ }^{30}$.

29 Véase en España, en el ámbito de la doctrina administrativista, por ejemplo, A. Huergo Lora (2007), Las sanciones administrativas, Madrid, pág. 394, propugnando una remisión matizada al Código Penal.

30 Puede ser significativo que conforme al art. 31 bis. 1 b) CP, son responsables las personas jurídicas, por los delitos cometidos «[...] en el ejercicio de actividades sociales y por cuenta y en beneficio directo o indirecto de las mismas, por quienes, estando sometidos a la autoridad de las personas físicas mencionadas en el párrafo anterior, han podido realizar los hechos por haberse incumplido gravemente por aquellos los 
En segundo lugar, la culpabilidad será particularmente patente, aunque no solo, en las hipótesis en las que el hecho protagonizado por la persona jurídica no se deba a la actuación particular de un sujeto enmarcado en aquella, sino a un cúmulo de incorrectas operaciones individuales de personas físicas insertas en la estructura propia del ente colectivo de que se trate ${ }^{31}$.

En tercer lugar, probablemente en este contexto deba plantearse la cuestión de si es suficiente para excluir la culpabilidad social con la existencia de instrucciones expresas por parte de quien tiene poder de dirección frente al trabajador a fin de que se abstenga de llevar a cabo la conducta (o, por el contrario, lleve a cabo una determinada acción que excluiría, por ejemplo, el resultado lesivo) que acaba desencadenando el correspondiente procedimiento penal. La cuestión no admite una toma de posición general, sino que depende del conjunto de circunstancias en las que cursan los acontecimientos y que implican valorar un conjunto amplio de elementos, como el énfasis con el que se emitieron las instrucciones, su claridad, las posibilidades de tomar medidas alternativas de vigilancia, la capacidad del sujeto que recibió las órdenes, los antecedentes de este, etc. Ello explica la disparidad de resoluciones jurisprudenciales en la experiencia del derecho comparado ${ }^{32}$.

deberes de supervisión, vigilancia y control de su actividad atendidas las concretas circunstancias del caso".

31 La construcción aquí aceptada posibilita diferenciar, en el caso de infracciones culposas, la imprudencia de la culpabilidad, concebida esta última como defecto de organización; la culpa requeriría un juicio individual, y la culpabilidad, uno referido a la organización concebida como ente colectivo.

32 Puede ser muy significativa alguna cita procedente de la jurisprudencia inglesa, ya que en esta última no hay una nítida diferenciación entre derecho administrativo sancionador y derecho penal. Lo atestigua, por ejemplo, el caso The Director General of Fair Trading $v$ Pioneer Concrete (UK) Ltd, también conocido como Ready Mixed concrete (no 2), 1995: los empleados de cuatro empresas acordaron fijar los precios de sus productos contra la expresa prohibición efectuada por sus compañías, sin que tales trabajadores informaran a sus superiores, concretamente al Consejo de Administración, de la práctica que estaban desarrollando, por lo que los directores y gerentes (the directing mind and will of the company) no fueron conscientes de lo que acaecía. Las empresas fueron condenadas, pese a que esas expresas instrucciones en la medida en que era la empresa la que se benefició de tales prácticas (criterio este último que para mí sería insuficiente para la condena); véase A. Pinto y M. Evans (2008), Corporate criminal liability, 2 ed., London, pág. 329. En la jurisprudencia norteamericana se ha llegado a conclusiones contradictorias; se cita frecuentemente el caso United States v. Hilton Hotels, en el que se sancionó a la empresa pese al reconocimiento de que el empleado había actuado contra las expresas instrucciones de la compañía e ignorando la política 
En cuarto lugar, entendemos que sistemáticamente es aquí, en la culpabilidad, donde deben considerarse algunos de los rasgos de las personas físicas realmente actuantes, $\mathrm{u}$ omitentes, como la presencia o ausencia de causas de disculpa, de inimputabilidad o error de prohibición. Sin embargo, la constatación de cualquiera de los elementos citados automáticamente no determinará la exclusión de la responsabilidad del ente, puesto que, precisamente, puede constituir un síntoma de una deficiente organización. Así, si una persona física sin conocimientos jurídicos suficientes adopta decisiones que afectan a la persona jurídica, bajo un error de prohibición, frecuentemente no estamos sino ante un síntoma de ese defecto de organización, en la medida en que se pudo haber contratado a una persona suficientemente cualificada ${ }^{33}$. Sin embargo, cabe la posibilidad de aceptar que existe una objetiva complejidad de la normativa aplicable al caso, por lo que es posible entender que hay un error de prohibición vencible o invencible que afectó a la persona jurídica ${ }^{34}$.

Por el contrario, si quien actúa, o deja de hacerlo en el caso de las omisiones, lo hace bajo un trastorno mental transitorio, estado de necesidad o impulsado por miedo insuperable, probablemente se pueda concluir que la infracción cometida no es consecuencia de un defecto de organización. Evidentemente, es inevitable un acto valorativo por parte del juzgador, como ocurre con la culpabilidad característica de las personas físicas dentro del mismo

de aquella — críticamente, véanse William S. Laufer (2006), Corporate bodies and guilty minds, Chicago, London, pág. 71; Kathleen B. Brickey, Corporate criminal liability, 2 ed., 1992, \$3.01—; no obstante, son excepcionales los casos en los que se ha excluido la responsabilidad (id., \$3:08); en semejante sentido, véase Pamela H. Bucy (1991: 1441), con cita de casos extraídos de la jurisprudencia de aquel país.

33 En ocasiones se ha sostenido que la estricta aplicación del principio de responsabilidad por representación, en virtud del cual la responsabilidad por los hechos cometidos por la persona física se trasladan a la persona jurídica para la que se actúa, determina que la exclusión de la imputabilidad de la primera se extienda a la segunda, véase, por ejemplo, M. Kremnitzer y K. Ghanayim (2001: 541).

34 La jurisprudencia, de hecho, en algunas ocasiones ha aceptado la posibilidad de un error de prohibición invencible, excluyente de la culpabilidad de una persona jurídica en múltiples ocasiones. Así, a título de muestra, puede hacerse referencia a la STS, Sala de lo Contencioso-Administrativo, de 8 de marzo de 1993. Asimismo, con posterioridad, la STS, Sala de lo Contencioso-Administrativo, de 18 de junio de 2007, FJ 3, en el marco de una infracción tributaria, sin mencionar expresamente el error de prohibición. Además de los que citamos, véanse ulteriores ejemplos jurisprudenciales en Alejandro Nieto (2012: 409 y ss.). Un ejemplo, ya citado, de error vencible que pudo influir en la culpabilidad de la persona jurídica sería el caso de la STS de 23 de marzo de 2005, Sala de lo Contencioso-Administrativo, FJ 15. 
derecho penal. Otra cosa es que, por ejemplo, el error de prohibición o la inimputabilidad de quienes actúan por cuenta de la empresa o de la persona jurídica puedan servir para adecuar la respuesta punitiva frente al ente colectivo. Lo expresado es coherente con el punto de vista conforme al cual las personas jurídicas constituyen unas realidades sustanciales, diversas de los miembros que las integran, de forma que su responsabilidad se dirime sobre la base de categorías que no son un mero trasunto de las características de las personas físicas ${ }^{35}$.

En quinto lugar, y en coherencia con lo expresado hasta este momento, debe considerarse en el juicio de culpabilidad de las personas jurídicas, el carácter doloso o imprudente de la persona física realmente actuante. Como hemos ya tenido ocasión de poner de manifiesto, no se puede extrapolar la construcción del delito, o de la infracción administrativa, dolosa o imprudente, cometidos por personas físicas a los llevados a cabo por personas jurídicas, puesto que claramente tales categorías están diseñadas para personas físicas. Por ello mismo, entiendo que el dolo y la imprudencia de la persona física actuante no son elementos del tipo, sino datos que deben ser considerados en la culpabilidad, entendida como defecto de organización. Evidentemente, tal defectuosa organización será mayor, más censurable, cuando la conducta del

35 La jurisprudencia del Tribunal Supremo en su Sala de lo Contencioso-Administrativo en alguna ocasión parece acoger de alguna manera la tesis aquí expuesta en cuanto a los elementos que tradicionalmente han integrado el juicio de culpabilidad. Así, en la STS de 3 de mayo de 1993, FJ 2º se sostiene que: "Conforme a esta última doctrina jurisprudencial, las entidades bancarias y crediticias son responsables administrativamente por la negligencia de sus empleados en el uso de las medidas de seguridad obligatoriamente instaladas en cumplimiento de las disposiciones vigentes, salvo cuando tal proceder no es consecuencia de la desatención sino de circunstancias o situaciones de riesgo personal grave para los propios empleados o terceras personas» (en igual sentido, véase STS de 20 de mayo de 1992, F. 4º). Asimismo, ya anteriormente, en la STS de 30 de junio de 1987, F. 2º se afirmaba que: «Es cierto que el incumplimiento de esta última obligación no puede generar responsabilidad administrativa para la empresa cuando la activación de las medidas instaladas entrańe un riesgo personal grave para sus empleados, como se ha dicho reiteradamente por este Tribunal, pero sí la determina, en contra de la conclusión a que llega la sentencia impugnada, cuando, como el caso de autos, al ocurrir los hechos — durante la noche del 11 de enero de 1983 - se encontraba desconectado el sistema de alarma antirrobo, por cuyo motivo no funcionó la alarma exterior». En definitiva, conforme se desprende de tal resolución, las causas de disculpa que puedan afectar a la persona física se trasladan a la persona jurídica con efectos exculpatorios. En general sobre la materia, puede verse M. Izquierdo Carrasco (2007: 40 y ss.). 
concreto sujeto físico que actúa sea intencional que cuando sea meramente imprudente ${ }^{36}$.

En sexto lugar, podemos ańadir, al menos, el nivel jerárquico del autor individual, el cual, en acertadas palabras de Nieto Martín, es un indicador bastante fiable del grado de culpabilidad de la empresa ${ }^{37}$.

Por último, será central la presencia o ausencia de un programa serio de cumplimiento. Formulado en otros términos, mal puede censurarse a una empresa un defecto organizativo, cuando se dotó a sí misma de un programa idóneo para prevenir la comisión de ilícitos en su seno (otra cosa es que se tenga programa y que, sin embargo, no sea un programa serio, ex ante eficaz o siéndolo, no se encuentre correctamente implementado ${ }^{38}$. No tiene sentido preventivo alguno que si un sujeto ha agotado todos los medios a su alcance para impedir la comisión de tales hechos, pese a ello se le sancione. Se trataría de un inaceptable e inconstitucional supuesto de responsabilidad objetiva ${ }^{39}$.

36 En España, entiendo que en sentido próximo se manifiesta A. Nieto Martín, quien defiende que estamos ante supuestos de defectos de organización más o menos graves (2008: 162). En Alemania se ha sostenido, incluso, la posibilidad de que, pese a la actuación dolosa de la persona física, la persona jurídica sea sancionada a título de culpa, G. Dannecker/Fischer-Frischt, Das EG-Kartellrecht in der Bussgeldpraxis, 1989, pág. 289, apud A. Nieto Martín (1995), "Ordenamiento comunitario y Derecho penal económico: relaciones en el presente y en el futuro", $A P$, 34, pág. 612, n. 61.

37 A. Nieto Martín (2008: 162). Tal criterio es recogido por el Código Penal en el art. 66 bis $2^{\mathrm{a}}$.

38 Gómez-Jara viene manteniendo una posición conforme a la cual el origen de la culpabilidad de las personas jurídicas radica en la generación de una cultura empresarial de incumplimiento (2012, «Fundamentos de la responsabilidad penal de las personas jurídicas», Tratado de responsabilidad penal de las personas jurídicas, págs. 117 y ss., 124, entre otras obras de este autor); precisamente por ello mantiene que los programas de cumplimiento son un indicio de una cultura empresarial determinada, por lo que pueden constituirse en la base de la exclusión de responsabilidad por ausencia de culpabilidad (id., pág. 115). Sobre esta construcción, véase B. Feijoo (2012), «Las características básicas de la responsabilidad penal de las personas jurídicas en el Código Penal español», Tratado de responsabilidad penal de las personas jurídicas, pág. 81, especialmente n. 40. No obstante, el mismo Gómez Jara defiende que responde a la tipicidad la idoneidad objetiva de los programas de cumplimiento (id., pág. 175).

39 Con razón, se ha afirmado que due diligence es lo contrario de culpabilidad (fault), véase J. Gobert y M. Punch (2003: 100). Entiendo que es la posición mayoritaria en la doctrina española; véase, por todos, por ejemplo, J. A. Lascuraín Sánchez (2013), "Compliance, debido control y unos refrescos», L. Arroyo Zapater y A. Nieto Martín (dirs.), El derecho penal económico en la era compliance, Valencia, pág. 212. 
A nivel positivo, no puede olvidarse que el art. 29.3 de la Ley 40/2915 dispone que «en la imposición de sanciones por las Administraciones Públicas se deberá observar la debida idoneidad y necesidad de la sanción a imponer». Mal puede haber necesidad de sanción en estos $\operatorname{casos}^{40}$.

Se plantea, pues, la cuestión de si la implantación de programas de cumplimiento, compliance programs, puede tener alguna operatividad en el marco del derecho administrativo sancionador, concretamente, excluyente o atenuante de la culpabilidad de la empresa. La cuestión, hasta donde alcanzo, apenas se ha analizado en Espańa. A ello dedicamos el apartado siguiente.

\section{ESPECIAL CONSIDERACIÓN DE LOS PROGRAMAS DE CUMPLIMIENTO ADOPTADOS CON CARÁCTER PREVIO A LA COMISIÓN DE LA INFRACCIÓN ADMINISTRATIVA}

Como hemos señalado, parece claro que es en el ámbito de la culpabilidad material donde se debe analizar si la adopción de programas de cumplimiento debe tener alguna clase de operatividad eximente o atenuante de la responsabilidad. Nos referimos a los casos en los que dicho programa de cumplimiento se haya adoptado antes de la comisión de la infracción administrativa $^{41} \mathrm{y}$, además, dicho programa sea idóneo ex ante para la prevención de su comisión. No nos ocupamos ahora de los casos de adopción a posteriori, en la medida en que tratándose de un hecho posterior a la comisión de la infracción no afecta a la infracción misma, ni a la culpabilidad del sujeto. En este último grupo de casos, entendemos que su eficacia atenuante dependerá de si

40 No deja de ser significativo que en derecho penal se haya identificado por algún autor la culpabilidad con la necesidad de imponer una pena cuando así lo exija el restablecimiento de la vigencia de la norma, esto es, fundada en la prevención general positiva (S. Bacigalupo Sagesse, 1998: particularmente, 169 y ss., 199 y ss., 398-399).

41 Las conclusiones apuntadas son idénticas con independencia de que el programa de cumplimiento se haya adoptado con anterioridad a la comisión de la infracción administrativa o con posterioridad a esta. No obstante, en este último caso, inequívocamente, y como ya hemos apuntado, tan solo podrá hablarse de una eficacia atenuante y no eximente, ya que, como hemos indicado supra, solo es posible apreciar excusas absolutorias cuando la Ley expresamente las contemple. Como circunstancia atenuante, al margen de cuestiones dogmáticas, desde un punto de vista positivo, entiendo que ningún problema habrá para aplicar analógicamente el art. 31 quater d) $\mathrm{CP}$ que contempla como circunstancia atenuante: «Haber establecido, antes del comienzo del juicio oral, medidas eficaces para prevenir y descubrir los delitos que en el futuro pudieran cometerse con los medios o bajo la cobertura de la persona jurídica». 
el derecho positivo ha establecido dicha posibilidad, bien específicamente en relación con las infracciones administrativas, bien en el derecho penal de las personas jurídicas, de aplicación, entendemos, analógica ${ }^{42}$.

Desde nuestra perspectiva, son cuatro, al menos, los argumentos para propugnar que los programas de cumplimiento adoptados antes de la comisión de la infracción tengan operatividad general para calcular la cantidad de sanción a imponer en el ámbito del derecho administrativo sancionador, como circunstancia atenuante (al amparo del art. 29.3 de la Ley 40/2015 de 1 de octubre de Régimen Jurídico del Sector Público que atiende al «grado de culpabilidad») o, incluso y de forma muy excepcional, para determinar la exclusión de la responsabilidad.

Por una parte, desde una perspectiva material, aceptado que forma parte del concepto de infracción administrativa la culpabilidad y concebida esta como defecto de organización, parece claro que dicho defecto dejará de existir en los casos en los que se haya implementado, antes de la comisión de la infracción administrativa, un programa de cumplimiento ex ante idóneo para prevenir la comisión de infracciones administrativas en el seno de la persona jurídica. No parece que se pueda cuestionar que existe una incompatibilidad conceptual entre déficit organizativo y existencia de un programa de cumplimiento idóneo. Reiteramos que si la organización hizo todo lo posible por evitar tal comisión de infracciones administrativas, y pese a ello, esta tuvo lugar, no tiene ningún sentido preventivo la imposición de sanción alguna, salvo que se incurra en una constitucionalmente censurable responsabilidad objetiva $^{43}$. Quien rechace el planteamiento expuesto, probablemente debería

42 La cuestión se ha planteado, especialmente, en la resolución del Consejo de la Comisión Nacional de los Mercados y la Competencia de 6 de septiembre de 2016, Expte. S/DC/0544/14, Mudanzas internacionales, 6.4.2. c), que citaremos a continuación. En cuanto al criterio de la aplicación analógica del Código Penal al derecho administrativo sancionador, véanse M. Gómez Tomillo e I. Sanz Rubiales (2017: caps. 2, 6 y passim); J. A. Santamaría Pastor (2016), Principios de Derecho administrativo general, $4 \mathrm{a}$ ed., t. II, pág. 447.

43 Esa es la censura que merece la posición de la Comisión Europea, el Tribunal General y el Tribunal de Justicia de la Unión Europea, los cuales, en principio, no admiten la adopción de programas de cumplimiento con efecto atenuante o eximente de responsabilidad. No obstante, debe tenerse en cuenta que la jurisprudencia europea viene siendo relativamente tibia, pudiendo interpretarse que, en casi todos los casos, es más un problema de acreditación de la idoneidad del programa que un descarte definitivo de su operatividad atenuante o excluyente de la responsabilidad. Por lo que concierne al Tribunal General de la Unión Europea, a título ejemplificativo, cabe la cita del caso IBP Ltd International Building Products France SA contra Comisión Eu- 
ropea, Sentencia de 24 marzo 2011 TJCE 2011175, par. 83: «En relación, en tercer lugar, con la alegación de que era aplicable el programa destinado a luchar contra las prácticas contrarias al juego de la libre competencia, debe señalarse que el hecho de que las demandantes aplicaran un «compliance programme» no pone en tela de juicio su participación en las reuniones anticompetitivas. Además, procede observar que no existe documento alguno del que se pueda inferir que se distancian públicamente de la práctica colusoria». El Tribunal General de la Unión Europea, caso Donau Chemie AG contra Comisión, Sentencia de 14 mayo 2014, TJCE 2014\194, par. 169, no es tan contundente: "[...] la mera adopción por parte de una empresa de un programa de sometimiento a las normas de la competencia no constituye una garantía válida y fiable de que esta vaya a respetar dichas normas en el futuro de modo duradero, de manera que un programa de este tipo no puede forzar a la Comisión a reducir la multa aduciendo que el objetivo de prevención que esta sanción persigue se ha alcanzado ya, al menos parcialmente (Sentencia Degussa/Comisión [TJCE 2006, 107], citada en el apdo. 66 supra, apdo. 361). Por otro lado, la demandante no ha invocado ningún elemento concreto que demuestre que el efecto disuasorio específico exigido podía alcanzarse con un importe de la multa menos elevado en el caso de empresas que han adoptado medidas de adecuación. Por tanto, aunque es del propio interés de una empresa adoptar tales medidas, en un esfuerzo de prevenir futuras infracciones de las normas sobre competencia y de evitar así las sanciones que esas infracciones justificarían, no cabe exigir, ni a la Comisión ni al Tribunal al ejercer su competencia jurisdiccional plena en materia de multas, que recompensen automática y sistemáticamente, mediante una reducción del importe de la multa, la adopción de las medidas en cuestión». Luego la recompensa no es automática, depende del caso ccntreto, no pudiendo descartarse, sin más, a priori su eficacia. En cuanto al TJUE, se pronuncia de forma aparentemente más contundente en el caso Dansk Rørindustri\Comisión, asunto C-501/11, par. 373, en el que se concluyó que «el Tribunal de Primera Instancia no cometió error de Derecho alguno al estimar en el citado apartado de dicha sentencia que, aunque era sin duda importante que LR A/S hubiera tomado medidas para impedir que los miembros de su personal cometieran en el futuro nuevas infracciones del Derecho comunitario de la competencia, este hecho en nada cambiaba la realidad de la infracción que había quedado probada en el caso de autos. El Tribunal de Primera Instancia actuó legítimamente al concluir que tal circunstancia no constituía, en sí, una circunstancia atenuante que obligase a la Comisión a reducir el importe de la multa a dicha recurrente». Menos contundente, por el contrario, se muestra en el asunto C-501/11 Schindler Holding y otros/Comisión, par. 144, en el que se lee: «[p] or lo que respecta al programa de adecuación establecido por el Grupo Schindler, es evidente que, como señaló la Abogado General en el punto 185 de sus conclusiones, no surtió efecto positivo sino que, por el contrario, dificultó el descubrimiento de las infracciones. De ello se desprende que el Tribunal no incurrió en un error de Derecho al desestimar la alegación de las recurrentes a ese respecto». Parece claro que ello no 
desarrollar un concepto de culpabilidad propio, no simplemente dejar la cuestión abierta ${ }^{44}$, mucho menos si, como tiene declarado el TC español, la culpabilidad constituye un requisito estructural del Estado de derecho (véanse, especialmente, SSTC 246/1991, de 19 de diciembre, FJ 2; 59/2008, de 14 de mayo, FJ 11 b); 185/2014 de 6 de noviembre, Fto. Jco. 30 in fine). Parece razonable, asimismo, que si dicho programa no fue plenamente idóneo, pero sí estimativamente significativo, se proceda a disminuir la sanción (reiteramos que en los términos del art. 29.3 de la Ley 40/2015).

Por otra parte, constituye incuestionablemente un deseable objetivo la generalización de la implantación de esta clase de instrumentos. Sin embargo,

equivale a una negativa a aceptar el programa como causa de atenuación o exención, sino la exclusión de su aplicación en el caso concreto.

En general, sobre la cuestión, véase P. Pérez Fernández (2014), «La importancia de los programas de cumplimiento (compliance programmes) en las políticas sancionadoras de las autoridades de competencia», Revista de Derecho Mercantil, 292, págs. 303 y ss., quien resalta que se ha producido un cambio de parecer, con cita de diversas resoluciones en las que se sostuvo otro criterio (págs. 304 y ss.). La autora cuestiona si dicha perspectiva es compatible con el principio de culpabilidad previsto en el art. 23.2 del Reglamento 1/2003 y que requiere la presencia de «negligencia» o una actuación «deliberada», lo cual no habría sido examinado por los citados órganos (págs. 308-310). De alguna forma coincidimos con su planteamiento. No obstante, dolo e imprudencia son categorías diseńadas esencialmente para personas físicas. Por ello mismo creemos que es más preciso entender, por una parte, que realmente lo que se está cuestionando es si concurre culpabilidad de empresa en cuanto que defecto de organización. La imprudencia del sujeto físico que realmente actúa u omite hacerlo, pensamos, sería un dato más a considerar en el juicio de culpabilidad.

No obstante, debe destacarse que es frecuente que el defecto de organización se considere como elemento del tipo y, pese a ello, se llegue a la misma conclusión expuesta en el texto, véanse J. L. de la Cuesta Arzamendi (2011: A-05: 8 y 16); I. Blanco Cordero (2012), El delito de blanqueo de capitales, págs. 855, 874 y 881; M. Bajo Fernández (2012), «Vigencia de la responsabilidad penal de las personas jurídicas en el Derecho sancionador español», Tratado de responsabilidad penal de las personas juridicas, pág. 34; N. J. de la Mata Barranco et al. (2011), «La atribución de responsabilidad penal a las personas jurídicas y su exención: instrumentos de prevención en el seno corporativo", La Ley Penal, 87, pág. 4. En general, no podemos compartir la idea de que el defecto de organización es una cuestión de injusticia, entre sin embargo, no haber peligrosidad otras razones, porque puede haber tal defecto de organización y, para los bienes jurídicos (por ejemplo, no se instauran medidas de control de los trabajadores que, sin embargo, desarrollan correctamente su trabajo). Sobre tales cuestiones, véase, por ejemplo, M. Gómez Tomillo (2016), Introducción a la responsabilidad penal de las personas juridicas, $2^{\mathrm{a}}$ ed., cap. 6.1. 
solo si se les concede alguna clase de operatividad real, las empresas estarán incentivadas a implementarlos ${ }^{45}$. Es claro que el simple prestigio reputacional no es suficiente para estimular su generalización, mucho menos si se tiene en cuenta que su coste puede ser elevado, como tampoco el potencial acceso a programas de clemencia ${ }^{46}$, en caso de detección precoz, entre otras razones porque, si no hay tal detección precoz, normalmente se perderá la posibilidad de obtener un mejor trato punitivo ${ }^{47}$.

En tercer lugar, no resulta razonable que en algunos ámbitos del derecho administrativo sancionador se le otorgue relevancia atenuante y eximente de responsabilidad a la adopción de tales programas y en otros no ${ }^{48}$. Un sistema que opera de semejante forma puede ser seriamente cuestionado en su coherencia interna ${ }^{49}$. La alternativa puede ser establecer su obligatoriedad y sancionar el incumplimiento de dicha obligación jurídica, confiando más en

45 Incluso se ha afirmado que de no conceder eficacia atenuante o eximente al programa, se desincentiva el hacerlo. Y ello en la medida en que normalmente debería concluirse que si se cometió el ilícito pese a su implantación, la conducta no fue negligente, sino intencional, y, por consiguiente, más grave, lo que debería repercutir en la cantidad de sanción a imponer (Pérez Fernández, 2014: 312-313). La cuestión admite, no obstante, muchos matices, en los que no podemos entrar.

46 Esa es la posición que expresa la CNMC: «esta Sala hace suya la consideración de la Comisión Europea de que la principal recompensa derivada de la introducción de tales programas, si se revelan eficaces, será la inexistencia de conductas contrarias a la competencia o, en el peor de los casos, su inmediata detección y las ventajas derivadas de poder hacer uso de los Programas de Clemencia» (Resolución CNMC de 6 de septiembre de 2016, expte. S/DC/0544/14, Mudanzas internacionales, 6.4.2. c); Resolución CNMC de 23 de julio de 2015, expte. S/0482/13, Fabricantes de automóviles 7.1).

47 Suscribimos la opinión de P. Pérez Fernández, la cual pone de relieve lo contradictorio de otorgar a los programas de clemencia en el derecho de la competencia un efecto atenuante $\mathrm{o}$ incluso eximente de responsabilidad y no conceder ni siquiera un efecto atenuante a la previa adopción de un programa de cumplimiento idóneo (2014: 312). No deja de ser significativo, por ejemplo, que el art. 179.2.d) LGT disponga que las acciones u omisiones tipificadas por la ley no dan lugar a responsabilidad tributaria, cuando se haya puesto la diligencia necesaria en el cumplimiento de las obligaciones tributarias. Aun cuando no contamos con una declaración ad hoc, dentro de esa «diligencia necesaria» cabe incluir conceptual y lingüísticamente también los casos que nos ocupan de adopción de programas de cumplimiento.

49 Véanse ejemplos de derecho comparado, específicamente de derecho de la competencia, en los que se otorga eficacia a los programas de cumplimiento, en P. Pérez Fernández (2014: 318 y ss.). 
la eficacia de un derecho represor que en la de un derecho premial ${ }^{50}$. Sin embargo, estimamos que, probablemente, lo más eficaz sería establecer dicha obligatoriedad solo en sectores particularmente sensibles y atribuir eficacia atenuante o eximente general a su adopción ${ }^{51}$.

Por fin, los programas de cumplimiento no son indiferentes desde la perspectiva del derecho administrativo sancionador, en la medida en que esta última rama del ordenamiento jurídico no puede permanecer, sin más, al margen de lo que acaece normativa y dogmáticamente en el ámbito del derecho penal. La razón reside en la unidad del derecho punitivo del Estado, el cual tiene que responder a iguales principios garantistas (aunque no a idénticas reglas ya que ni siquiera dentro del derecho penal en sentido estricto las reglas son homogéneas). Pero es que, en todo caso, se admita o no la unidad entre ambos sectores del ordenamiento jurídico, entendemos que no tiene mucho sentido que si en el derecho penal se concede alguna clase de operatividad a los programas de cumplimiento, en el derecho administrativo sancionador simplemente se les ignore, cuando estamos ante una rama del ordenamiento jurídico orientada a la imposición de sanciones que pueden alcanzar una gravedad muy superior a la prevista en el mismo Código Penal ${ }^{52}$.

Partiendo de los anteriores puntos de vista, la conclusión se impone por sí misma: no debería existir una solución diversa en el derecho penal y en el derecho administrativo sancionador en esta materia. En la actualidad, y a falta de una más que deseable Ley general de infracciones y sanciones administrativas, no se contempla con carácter general (a salvo de determinados sectores muy concretos) en el derecho administrativo sancionador positivo la posibilidad de proceder a una disminución o eliminación de la sanción en el

50 El primero es el camino que se ha seguido en Alemania, por medio del par. 130 $O W i G$. En España, en materia de seguridad e higiene en el trabajo, véase el art. 12.1 del Real Decreto Legislativo 5/2000, de 4 de agosto, por el que se aprueba el texto refundido de la Ley sobre Infracciones y Sanciones en el Orden Social. Por lo que concierne al blanqueo de capitales, requiere una combinación de normas establecidas en la Ley 10/2010, de 28 de abril, de prevención del blanqueo de capitales y de la financiación del terrorismo. Concretamente, deben considerarse los arts. 26.1, $52 \mathrm{~m}$ ) y 54 de la citada ley, los cuales presentan su específica problemática en cuyos detalles no podemos entrar.

51 Sobre la cuestión, véase, entre otros, M. Gómez Tomillo (2016), Compliance penal y politica legislativa, passim.

52 Resulta, al respecto, particularmente interesante el desarrollo de la cuestión en el derecho norteamericano, donde la existencia de tales programas influyen no solo en las penas en sentido estricto a las empresas, sino también en el alcance de las allí llamadas sanciones civiles; al respecto, véase M. Engelhardt (2010: 286). 
caso de que la persona jurídica haya adoptado medidas eficaces orientadas a la prevención de infracciones administrativas. Sin embargo, en la medida en que la Ley administrativa no solucione expresamente la cuestión siempre cabrá acudir al derecho penal por medio de un razonamiento analógico, siempre en beneficio del infractor, en este caso la persona jurídica ${ }^{53}$. En definitiva, una vez más, no es indiferente el estado de la cuestión en derecho penal, tal y como la hemos expuesto. Si se acepta que los programas pueden llegar a tener eficacia eximente de la responsabilidad penal, no vemos por qué no debe operarse de igual modo en derecho administrativo sancionador ${ }^{54}$, singularmente a la vista de la literalidad del ya tantas veces citado art. 29.3 a) de la Ley 40/2015, «grado de culpabilidad», de donde parece desprenderse que sin culpabilidad no hay sanción posible (dejando al margen cuestiones constitucionales).

Asumido lo anterior, solo resta poner de manifiesto que, como es conocido, en el derecho penal español positivo, la implantación de un programa de cumplimiento idóneo para prevenir la comisión de delitos opera excluyendo la responsabilidad en los términos del art. 31 bis 2 y 31 bis $4 \mathrm{CP}$ o atenuándola en los del art. 31 bis 2, párrafo último CP.

Partiendo de los anteriores postulados, debe tenerse en cuenta que en los supuestos de actos ilícitos llevados a cabo por los representantes legales o altos directivos, en nombre o por cuenta de la empresa, paradigma de hipótesis de responsabilidad penal o administrativa de la persona jurídica, resultará particularmente difícil que un programa de cumplimiento pueda tener en la

53 Entiendo que es el criterio que, quizá de forma un poco escasa, adopta la CNMC, cuando en la Resolución CNMC de 6 de septiembre de 2016, expte. S/DC/0544/14, Mudanzas internacionales, 6.4.2. c), in fine, afirma: «[n]o cabe duda de la conveniencia de que se realice una interpretación integradora y armonizadora de las normas de nuestro ordenamiento jurídico, en lo relativo a derecho penal y derecho administrativo sancionador..., pero tal interpretación no permite en este caso admitir la pretensión de aplicación analógica de la atenuante del Código Penal, puesto que no concurren los elementos que esta norma establece a tal efecto, sin perjuicio de que el hecho de la adopción de un programa de cumplimiento pueda ser tenido en cuenta en este caso para modular la sanción".

54 En palabras de A. Nieto, «la responsabilidad penal de las personas jurídicas tiene como finalidad motivar a que las empresas incrementen su nivel de autorregulación y establezcan mecanismos necesarios de gestión, organización y control para evitar la comisión de hechos delictivos... En este sentido son claves los compliance programs o modelos de organización» (2008: 215). Evidentemente, el criterio es extrapolable al ámbito que nos ocupa en el que no nos cabe duda de que los programas de cumplimiento deberían tener eficacia eximente, siempre que, ex ante, se tratase de eficaces métodos de control de conductas antijurídicas. 
práctica operatividad como atenuante o eximente ${ }^{55}$. Dicho con otras palabras, desde un punto de vista puramente estadístico, parece razonable entender que su operatividad jurídica entrará sobre todo en juego en el caso de conductas cometidas por empleados sin poder de dirección y, especialmente, aunque no solo, en el caso de conductas imprudentes, más que en las dolosas ${ }^{56}$.

Con independencia de que la concreta infracción haya sido cometida por persona que ocupe una posición dirigente o subordinada en la estructura empresarial o social, parece claro que la idoneidad del programa para impedir la verificación de infracciones administrativas en el marco de la persona jurídica debe contemplarse desde una perspectiva ex ante, aunque ex post tal programa no haya sido suficiente. Lo que no cabe racionalmente es la exigencia de un compliance perfecto, sin fisuras, que, con toda probabilidad, sería incompatible con un ejercicio razonablemente eficaz de las tareas empresariales ${ }^{57}$. Creo que esa es la posición de la CNMC cuando en su resolución afirma que «el mero hecho de introducir estos programas internos de adecuación a las normas sobre competencia no puede tomarse sin más como una circunstancia atenuante, sobre todo en aquellos casos en los que la acreditación de una infracción es una evidencia clara para las empresas sancionadas de un fallo en el cumplimiento de tales normas internas ${ }^{58}$. Entiendo que no cabe sostener que la infracción es una prueba irrefutable de que el programa era insuficiente. La existencia de la infracción es solo un indicio de que el programa no era el adecuado, pero es posible imaginar múltiples circunstancias en las que la infracción no era evitable y, precisamente por ello, no hubo culpabilidad empresarial. La cuestión, entiendo, se solventa correctamente con las reglas de la carga de la prueba. Si lo normal es que se haya verificado la infracción por la inexistencia de un programa idóneo ex ante, lo adecuado es trasladar al infractor la carga de probar que se cometió la infracción, pese a la corrección de tal compliance program.

Del mismo modo, y como es obvio, un programa de cumplimiento meramente cosmético no debería determinar la exclusión, ni siquiera la aminoración, de la responsabilidad de la empresa.

En la práctica va a resultar particularmente complejo acreditar en el caso concreto que el programa fue objetivamente idóneo para impedir la comisión

55 En sentido próximo, William S. Laufer (2006: 129).

56 En el caso de directivos, probablemente con razón, diferencia en función de si se trata de varios administradores o de uno solo J. A. Lascuraín (2013: 120-121).

57 Sobre la conexión del programa de cumplimiento y el riesgo permitido, véase J. M. Palma Herrera (2014: 207-208).

58 Resolución CNMC de 6 de septiembre de 2016, expte. S/DC/0544/14, Mudanzas internacionales $6.4 .2 \mathrm{c}$ ), pág. 103. 
de delitos o infracciones administrativas ${ }^{59} \mathrm{y}$, por consiguiente, que tenga eficacia eximente de responsabilidad (no así la atenuante). Como expresaremos a continuación, entendemos que corre de cargo de la persona jurídica la prueba de una organización no defectuosa, lo que permite pensar que la plena exención de responsabilidad será una situación excepcional, aunque no imposible. Debe tenerse en cuenta que en la mayor parte de las ocasiones la verificación del delito o de la infracción administrativa será un síntoma de que el programa no estaba correctamente diseñado. Solo cabe entender como excepcional el que el programa esté correctamente diseñado e implementado y, pese a ello, el delito o la infracción se cometa. La experiencia del derecho comparado parece corroborar lo expuesto ${ }^{60}$. Evidentemente se trata de fomentar el que se implanten programas de cumplimiento eficaces, no de crear mecanismos de impunidad para las personas jurídicas ${ }^{61}$.

Si se aceptan los anteriores puntos de vista, se presenta el problema de la medida de la disminución de la sanción administrativa a favor de la persona jurídica que haya adoptado un eficaz programa de cumplimiento. Tal problema está presente en tanto que, como hemos puesto de manifiesto, la Ley administrativa normalmente no contempla como circunstancia atenuante, ni mucho menos como eximente, la adopción de tales programas. Desde nuestra perspectiva, cuanto menos, la sanción no debería sobrepasar el umbral mínimo establecido en la Ley. No obstante, tanto por razones de proporcionalidad, a la vista de lo dispuesto en el art. 29.4 de la Ley $40 / 2015^{62}$, como por aplicación analógica de las reglas del Código Penal,

59 Subraya E. Bacigalupo las dificultades para que se pueda apreciar la circunstancia atenuante de haber establecido antes del juicio oral medidas eficaces para prevenir y descubrir los delitos que en el futuro pudieran cometerse con los medios o bajo la cobertura de la persona jurídica. Indica, con razón, que difícilmente podrá ser apreciada sin una prueba pericial, dado que el juicio que requiere no es solo jurídico. Como el mismo Bacigalupo afirma: «el objeto de la prueba es el mismo que la requerida para acreditar la no reprochabilidad de la organización», E. Bacigalupo Zapater (2011), Compliance y Derecho penal, pág. 95.

60 Aunque no se trate de datos plenamente actualizados, véase William S. Laufer (2006: 119), donde pone de manifiesto que en el periodo comprendido entre 1996 y 2004 solo dos de las compañías condenadas tenían un programa de cumplimiento realmente efectivo (recuérdese que apenas hay una diferencia entre delitos e infracciones administrativas en el derecho anglosajón).

61 Lo que es una idea global; véase en igual sentido William S. Laufer (2006: 189).

62 Para el cálculo de la sanción en el grado inferior, conforme a lo establecido en dicha norma, véase T. Cano Campos (2016), «El autismo del legislador: la "nueva” regulación de la potestad sancionadora de la Administración», RAP, 201, pág. 50. 
debería en tales casos plantearse desbordar hacia abajo ese umbral (véanse los arts. 66.1 y 66 bis CP).

\section{LA CUESTIÓN DE LA CARGA DE LA PRUEBA}

Lo expresado nos lleva a la cuestión de la carga de la prueba de la idoneidad ex ante del programa para evitar la comisión de ilícitos en el seno empresarial. Lo examinaremos desde la perspectiva particular de los programas de cumplimiento, si bien lo afirmado es válido para cualquier otro de los elementos integrantes de la culpabilidad de las personas jurídicas que hemos descrito. Desde nuestra perspectiva, la carga de la prueba de la concurrencia de circunstancias que la excluyen recae sobre la misma persona jurídica infractora $^{63}$. Las razones para ello son múltiples.

En primer lugar, es razonable eximir de la prueba a aquello que resulta excepcional: se puede presumir lo que es normal. Como hemos expresado ya, en la mayor parte de las ocasiones la verificación de la infracción (o, en su caso, del delito) será un síntoma de que el programa no estaba correctamente diseñado. Solo excepcionalmente habrá un programa correctamente diseñado e implementado y, pese a ello, se cometa el ilícito o lo que es lo mismo, la plena exención de responsabilidad será una situación excepcional, aunque no imposible (no así la mera atenuación).

En segundo lugar, porque en la práctica no resulta factible que recaiga sobre la Administración la prueba de un elemento negativo: la ausencia de una organización defectuosa. Lo contrario supondría cargarla con una imposible probatio diabolica ${ }^{64}$.

En tercer lugar, hay evidentes razones prácticas, puesto que es la empresa la que tiene en su mano la información precisa para acreditarlo: el compliance program, la información sobre a quién se nombró oficial de cumplimiento, la existencia de actualizaciones de dicho programa, quién era el encargado de llevar a cabo una determinada tarea, por qué razones se le nombró, con qué criterios, etc. Resulta artificial trasladar a la acusación la carga de probar lo que se encuentra fácilmente a disposición de la persona jurídica.

63 En el ámbito sancionador administrativo parecen compartir el mismo planteamiento I. López Carcamo e I. Lasagabaster Herrarte (2006: 197).

64 Otro criterio en V. Gómez Martín (2012), «Falsa alarma. O sobre por qué la Ley Orgánica 5/2010 no deroga el principio societas delinquere non potest», S. Mir Puig y M. Corcoy Bidasolo (dirs.), Garantías constitucionales y Derecho penal europeo, pág. 252. 
Por último, lo aquí defendido se encuentra en línea con lo que es frecuentísimo en el derecho anglosajón en lo que concierne a la due diligence defence sin que allí se cuestione la vulneración de garantías fundamentales ${ }^{65}$.

Pese a lo expuesto, en materia penal, el Tribunal Supremo viene manteniendo un criterio muy diverso. Como hemos expresado, el Alto Tribunal parte de la expresada posición de acuerdo con la cual para la exigencia de responsabilidad penal de la persona jurídica se ha de analizar si el delito cometido por la persona física en el seno de aquella "ha sido posible, o facilitado, por la ausencia de una cultura de respeto al Derecho». Dentro de esa cultura de respeto se incluiría la implementación de un adecuado programa de cumplimiento (véanse SSTS 154/2016 de 29 de febrero o en la 221/2016 de 16 de marzo, FJ 5, in fine). En ese contexto, llega a la conclusión conforme a la cual es la acusación la que debe acreditar la ausencia de esa cultura de respeto de la legalidad o la inexistencia, inadecuación o falta de actualización de los programas de cumplimiento. En palabras de la propia STS 154/2016 de 29 de febrero: «en la práctica, será la propia persona jurídica la que apoye su defensa en la acreditación de la real existencia de modelos de prevención adecuados, reveladores de la referida "cultura de cumplimiento" que la norma penal persigue, lo que no puede sostenerse es que esa actuación pese, como obligación ineludible, sobre la sometida al procedimiento penal, ya que ello equivaldría a que, en el caso de la persona jurídica, no rijan los principios básicos de nuestro sistema de enjuiciamiento penal, tales como el de la exclusión de una responsabilidad objetiva o automática o el de la no responsabilidad por el hecho ajeno" ${ }^{66}$. Es claro que, trasladado dicho criterio al ámbito que nos ocupa, equivaldría a exigir que fuese la Administración la que acreditase caso por caso que la verificación de la infracción administrativa se debió a esa ausencia de cultura de cumplimiento, traducida en la ausencia de medidas orientadas a impedir dicha comisión. Apenas requiere un esfuerzo agumentativo poner de manifiesto lo inviable de dicho punto de vista.

65 Véanse J. Gobert y M. Punch (2003: 100-102); Law Commission Working Paper, Consultation Paper 195, Criminal liability in regulatory contexts, 1.68; 1.69, 6.1, 6.19, etc. Celia Wells (2001: 102), con cita del caso de referencia, Tesco v. Nattrass, de evidente proximidad con nuestro derecho administrativo sancionador.

66 Sin embargo, el criterio del voto particular a dicha sentencia es el contrario. 